\title{
JOVENS AMERICANOS, SUÍÇOS, AUSTRALIANOS, BRASILEIROS E FRANCESES FALAM SOBRE SUAS ESPERANÇAS E ASPIRAÇÕES PARA O FUTURO ${ }^{13}$
}

Nigel F. Bagnall ${ }^{14}$

\section{Resumo}

O prolongamento do período da vida referido a juventude é bem documentado e aceito na literatura relativa aos jovens. Dwyer e Wynn (2001) escreveram sobre o novo significado da fase adulta e o problema enfrentado pelos jovens ao fazerem a transição para uma zona alvo que está em constante mudança. A certeza de uma transição suave para a fase adulta não é mais garantida, se é que um dia já o foi. Este estudo analisa um grupo de jovens pertencentes ao que é frequentemente referido como a fase de transição para a vida adulta. Os jovens provêm de cinco países, em quatro continentes diferentes: Brasil, França, Suíça, Austrália e Estados Unidos da América. Os indivíduos entrevistados tinham entre 18 e 30 anos de idade e responderam a uma variedade de perguntas relacionadas às suas perspectivas, esperanças e aspirações para o futuro.

Palavras-chave: Transição. Juventude. Educação. Pertencimento.

\section{Abstract}

The prolongation of that period of life referred to as youth is well documented and accepted in the literature relating to youth. Dwyer and Wynn (2001) wrote of the new meaning of adulthood and the problem facing youth as they make a transition to a target zone that is constantly changing. The certainty of making a smooth transition to adulthood is no longer, if it ever were, assured. This study looks at a number of youth in what is often referred to as the transition phase to adulthood. They are in five different countries Brazil, France, Switzerland, Australia, and United States of America on four different continents. The individuals interviewed were generally between $18-30$ years of age. They were asked a variety of questions relating to their prospects, hopes and aspirations for the future.

Keywords: Transition. Youth. Education. Belonging.

\footnotetext{
${ }^{13}$ Tradução realizada por Giovana Mello e Bruno Leivas, do Labestrad/UFF (Laboratório de Estudos da Tradução da UFF). Revisão realizada por Adriane Matos de Araujo (Universidade do Estado do Rio de Janeiro)

14 Universidade de Sidney. E-mail : nigel.bagnall@sydney.edu.au
} 


\section{RevistAleph}

\section{Introdução}

Este estudo sobre as esperanças dos jovens para o futuro baseia-se claramente em um trabalho anterior, realizado pelo autor deste artigo, sobre os jovens e suas percepções de identidade e de pertencimento (Bagnall, 2015). No estudo anterior, o foco do estudo qualitativo foi a exploração das fronteiras da identidade. Em particular, o ponto central foi a identidade de estudantes em escolas internacionais em relação ao desenvolvimento de um sentimento de pertencimento global, em vez de nacional. Todos os estudantes que participaram desse estudo anterior eram de escolas internacionais de seis lugares diferentes. Foram identificadas para esses alunos uma das três identidades classificadas como nacional, global ou incerta. O foco inicial era observar qual o impacto causado por um movimento constante, a cada três anos aproximadamente, sobre os estudantes e seu sentimento de pertencimento. O grupo de alunos participantes fazia parte de escolas internacionais em três continentes diferentes: Ásia, Europa e América do Sul. As escolas situavam-se no Rio de Janeiro, Paris, Berlim, Londres, Genebra (duas escolas) e Manila.

Dentre as perguntas feitas aos estudantes estava onde achavam que estariam em um espaço de cinco anos e de dez anos. Tornou-se claro, a partir das respostas, que os estudantes podiam se adaptar e viam o mundo mais como um lugar de destino do que como um país em particular. Os estudantes, geralmente, não eram restringidos por preocupações geográficas ou econômicas, e seu futuro local de estudo dependia de uma série de fatores, os quais incluíam onde já haviam vivido, o que esperavam estudar e, assim como Zhanira, que estudava em uma escola internacional em Londres, havia o desejo de continuar os estudos em “...um local que fosse benéfico para aspirações profissionais futuras". (Bagnall, 2015, p. 91).

Este novo estudo sobre as esperanças dos jovens para o futuro se baseia e, de muitas formas, é uma continuação do estudo anterior. Os jovens participantes da nova pesquisa formam um grupo mais velho do que o daquele do estudo sobre a identidade. Os estudantes têm idade entre 18 e 30 anos, predominantemente, e vivem na França, Suíça, Austrália, EUA e Brasil. Este estudo aceita a noção de prolongamento da transferência da juventude para a fase adulta, sendo a extensão entendida como o resultado de uma série de marcos importantes, cada vez mais difíceis de alcançar. Tais marcos são 


\section{RevistAleph}

frequentemente resumidos como a conclusão da educação formal, a conquista da independência financeira e a saída da casa da família com a possível formação de um vínculo emocional com outra pessoa. Como Miles (2000, p. 9) observa, “... um termochave no desenvolvimento de qualquer compreensão adequada do estilo de vida dos jovens é o de 'transição', o processo pelo qual os jovens conseguem, de algum modo, atingir a fase adulta". O estudo ora apresentado diz respeito ao processo de transição, visto que este se projeta no futuro.

O grupo de jovens participantes deste estudo é bem diferente do anterior em vários aspectos. Todos os 82 estudantes da pesquisa anterior eram de escolas internacionais e tinham entre 16 e 19 anos de idade. A maioria estava no último ano da escola e estava prestes a se mudar pela primeira vez para um destino que não havia sido escolhido ou baseado predominantemente nos requisitos de trabalho dos pais. A escolha do local onde frequentariam a universidade representou, possivelmente, a primeira vez em que tiveram que tomar uma decisão independente, e as razões dadas para a escolha do local eram muitas e variadas. Raquel, estudante de uma escola internacional no Rio de Janeiro, representou a opinião de vários alunos quando disse:

... a Europa não seria um problema. Estive em Paris e pela França, e adorei. Mas eu tenho a sensação de que a Itália seria como aqui. A França é muito boa em engenharia. Talvez até mesmo a Austrália fosse uma boa, principalmente se eu tivesse um lugar grande para morar. Não pensei muito na Ásia.

O estudo mais recente sobre as esperanças dos jovens para o futuro analisa os estudantes em cinco países e quatro continentes diferentes. Alguns alunos trabalham, outros estudam e há, ainda, aqueles que estão tentando decidir exatamente o que gostariam de fazer.

\section{Fundamentação}

O mundo cada vez mais interconectado cria tensão em relação às preocupações com as novas maneiras de ver e de estar no mundo. O mundo surreal do Facebook, do Twitter e do Instagram e, de fato, todas as formas de mídias sociais disponibilizadas na internet, levaram a uma possível conformidade dentro do mundo físico. Há uma tensão inevitável entre as forças da homogeneização e da diversidade. Os sinais visíveis de 


\section{RevistAleph}

conformidade são facilmente identificáveis à medida que os/as jovens despreocupados de Praga curtem a vida em seus jeans Ksubi, falando ou enviando mensagens pelo iPhone, ou algo equivalente, e ouvindo músicas de uma coleção eclética da vasta biblioteca do iTunes. O mesmo visual virtualmente indistinguível é imitado em Nova York, Nova Deli, Sydney e Rio de Janeiro. Mas será que todos esses jovens pensam da mesma maneira sobre o futuro?

É concebível que este mundo em que os jovens atualmente estão entrando se torne um lugar onde as fronteiras não sejam mais desenhadas em termos de conhecidas linhas divisórias nacionais, mas em termos de conexões globais que refletem diferentes níveis de realidade física e espacial. Uma fronteira nacional, ou qualquer outra entidade geográfica, certamente não restringe o movimento de ideias e de criação de identidade para a juventude. A fundação da Comunidade Europeia (CE) foi anunciada como uma força potencialmente unificadora para todos os países membros. Essa concepção de identidade europeia pode reverberar em alguns países dentro da CE. Contudo, é possível desafiar qualquer pessoa a dizer a um/a grego/a que sua identidade está destinada a ser similar à identidade dos jovens alemães, franceses ou de qualquer outro país membro. A formação de identidade é um processo complexo e, embora seja possível ver mais semelhanças do que diferenças entre os jovens da Europa e os da América do Sul, por exemplo, as diferenças existem.

Para uma cobertura abrangente do aspecto de mobilidade crescente dos jovens no que diz respeito a suas carreiras, o estudo de David Cairns (2014) sobre mobilidade e reflexividade espacial é um bom ponto de partida. Seu livro analisa a necessidade de os membros das nações europeias, em particular, estarem cientes de que estão entrando em um mercado de trabalho global. Nas palavras do autor:

No nível da geopolítica, também precisamos estar cientes de que a facilidade com que os jovens se movimentam, incluindo a permissão e a inibição da mobilidade estudantil, é afetada por batalhas ideológicas, que ocorrem nos níveis de governo nacional e europeu (Cairns, 2014, p. 41).

O estudo de Cairns trata predominantemente de jovens europeus, com grande parte da pesquisa realizada em Portugal. A rica tradição de intercâmbio cultural e profissional na Comunidade Europeia, com programas como o Erasmus, Leonardo da Vinci e o mais recente Youth on the Move (YOTM), tornam o processo de transição para muitos 


\section{RevistAleph}

estudantes e jovens na Europa, que procuram por oportunidades de emprego, mais fácil de acessar do que em muitos países. O governo brasileiro também é generoso em termos de financiamento para estudantes que desejam passar algum tempo no exterior em alguma fase da educação universitária ${ }^{15}$. Em contraste, os estudantes de instituições australianas que procuram estudar no exterior parecem ter uma gama mais limitada de opções. O presente estudo analisa as esperanças e aspirações de estudantes universitários do Brasil, da Austrália, dos EUA, da Suíça e da França, na tentativa de mostrar como suas percepções sobre o futuro podem não ser mais ser influenciadas por paradigmas do passado.

Poucas pesquisas sobre isso são feitas no Brasil, a sexta maior economia mundial. As pesquisas realizadas estão geralmente focadas nas desigualdades que existem no país e, raramente, é dada voz às esperanças e aspirações dos jovens. O mesmo poderia ser dito da França, embora muitos teóricos da Sociologia venham desse país. O trabalho de Bourdieu sobre a teoria da reprodução social tem sido bem utilizado por sociólogos e jovens escritores há anos. A Suíça representa um oásis dentro da Europa a partir da CE, permanecendo no estudo como um elemento de comparação significativo. Os jovens da Suíça estão bem localizados para tirarem vantagem de sua posição na Europa. O último país para o estudo de caso deste artigo, a Austrália, continuou a desafiar as tendências econômicas mundiais, mas mantém muitos dos problemas no que se refere à entrada dos jovens no mercado de trabalho.

Por vezes referida como a "nova fase adulta", com os estudantes ficando na casa dos pais por mais tempo, casando-se mais tarde e com o surgimento de diversos padrões de transição para a fase adulta, todos esses padrões de envolvimento com a sociedade são mesclados neste estudo. (Bagnall, 2005, 2012, 2015).

Como Miles (2000, p. 9) observa: “[...]um termo-chave no desenvolvimento de qualquer compreensão adequada do estilo de vida dos jovens é o de 'transição', o processo pelo qual os jovens conseguem, de algum modo, atingir a fase adulta". Este estudo ocupa-se do processo de transição, uma vez que este se projeta no futuro.

\footnotetext{
${ }^{15}$ Nota da editora: Importante destacar que a pesquisa foi realizada num momento político brasileiro em que o programa de mobilidade universitária para outros países era incentivado pelo governo federal com bolsas de estudo, o que não vem mais ocorrendo no governo atual.
} 


\section{RevistAleph}

Chopra e Gajjala (2011), em Global Media, Culture and Identity: Theory, Cases, and Approaches (Mídia Global, Cultura e Identidade: teoria, casos e abordagens, em português), estão particularmente interessados no futuro da mídia e analisam predominantemente como identidade, cultura, mídia e globalização podem ser entendidas em nosso mundo de mudanças constantes. A abordagem de Chopra baseia-se em três proposições relacionadas. Em primeiro lugar, no momento histórico atual, a mídia global é central para a produção da identidade cultural. Em segundo lugar, essa identificação cultural é um motor essencial da lógica e do conteúdo dos fluxos midiáticos e, em terceiro lugar, as expressões da identidade cultural nos textos midiáticos podem ser lidas como reflexo da consciência global. (CHOPRA; GAJJALA, 2011, p.1).

Trudie Knijin sugere existirem três paradigmas de políticas, propostos por Schmid (2006), que são úteis na visualização de transições de trabalho para a fase adulta. 0 primeiro modelo de mercado de trabalho transicional baseia-se no pressuposto de que os mercados de trabalho pós-industriais em funcionamento em uma economia baseada no conhecimento exigem “...uma mão de obra flexível, inovação contínua e funcionários com tempo para treinamento, educação e assistência". (SCHMID, 2006 em KNIJIN, J., 2012, p. 23).

Os outros dois paradigmas de políticas propostos por Schmid são o modelo de curso de vida individual e o paradigma da investigação social. Cada um dos três paradigmas "...incorpora as necessidades e os riscos do capitalismo de bem-estar pósindustrial com quatro palavras-chave: novos riscos sociais, curso de vida, remercantilização e capital humano" (ibid, p. 25). A questão principal de Schmid é se esses riscos sociais são categorizados como resultado das escolhas dos próprios jovens ou se é mais provável que advenham de circunstâncias externas e fora do controle deles. Nas palavras de Schmid "...as altas taxas de evasão estão relacionadas a escolhas individuais dos alunos ou a sistemas escolares aquém do ideal?" (ibid)

A palavra-chave dos três paradigmas de políticas sugeridos por Schmid é o capital humano:

[...] embora tenha um significado distinto em cada um... no geral significa que trabalhadores individuais têm de assumir a responsabilidade pela sua empregabilidade, apoiados por programas de educação e treinamento financiados pública, coletiva ou individualmente (KNIJIN, 2012, p. 29). 


\section{RevistAleph}

A Comissão Europeia (CE) também enfatizou que na Europa nunca houve um crescimento econômico significativo sem um crescimento populacional. No presente, a média de pessoas nascidas na Europa anualmente é mais baixa do que o desejado.

\section{Metodologia}

Conforme observado anteriormente neste artigo, existem muitas áreas de trabalho acadêmico que ajudam a estruturar um estudo como este. Elas incluem, mas não estão restritas, à Psicologia, aos Estudos Culturais, à Antropologia, à Sociologia e à História. Este trabalho é um estudo internacional qualitativo e comparativo. Creswell e Plano Clarke (2007) observam que dados qualitativos são compostos por questões abertas, reunidas principalmente a partir de entrevistas com os participantes. Os alunos estudados nesta pesquisa respondem com suas próprias palavras. Dados adicionais também podem ser reunidos a partir da observação dos participantes durante um período de tempo em uma variedade de lugares. A análise dos dados qualitativos (palavras, textos ou imagens) geralmente ocorre após a classificação das palavras ou das imagens em categorias de informação e da apresentação da diversidade de ideias reunidas no decorrer da coleta de dados.

O papel do pesquisador é mais significativo em pesquisas internacionais e comparativas, como Landis et al. (2004, p.155) apontam. É uma questão da relatividade de valores e de sua imposição sobre os dados. O auto-posicionamento do pesquisador é significativo na interpretação das práticas discursivas multilíngues.

Giampapa; Lamoureux (2011, p. 127) observam que

[...] as identidades do pesquisador, as questões de posicionamento (ou seja, auto-posicionamento, o posicionamento dos outros e como somos posicionados pelos outros na área), o gênero, o poder da linguagem, e a autonomia fazem parte do processo de compreender e interpretar as práticas discursivas multilíngues.

Os autores se referem em particular a um estudo anterior de Mullings (1999), que descobriu ser o conhecimento do pesquisador sempre parcial por conta de seu posicionamento. Isso se refere ao seu conjunto único de raça, gênero, classe, nacionalidade e outros identificadores. 


\section{RevistAleph}

Ao escrever sobre o livro editado por Markauskaite, Freebody e Irwin (2011) acerca da metodologia de pesquisa, o autor deste artigo notou a necessidade de os estudiosos comparatistas conhecerem suas limitações enquanto pesquisadores e de se posicionarem no estudo. Foram observados quatro pontos-chave que devem ser considerados:

1. Conheça sua própria cultura;

2. Conheça o máximo que puder sobre a cultura ou sobre as culturas que estuda (língua, costumes, história, política, esportes, etc.);

3. Desafie constantemente as suposições (ex.: os franceses são arrogantes, os alemães são extremamente organizados, os australianos são sociáveis, os habitantes do Laos são gentis);

4. Avalie seus pontos fortes e fracos e foque nos seus pontos fortes. (MARKAUSKAITE, FREEBODY, IRWIN, 2011, p. 2014).

\section{Brasil}

Por que pesquisar os alunos do Rio de Janeiro? Existem muitas razões pelas quais o estudo do Brasil é importante neste artigo. Como mencionado anteriormente, o Brasil é um país em desenvolvimento, cuja economia está atualmente na oitava posição do ranking mundial. Há muitas discrepâncias que caracterizam o alcance da distribuição de tal riqueza, e nenhuma outra exemplifica mais esse quadro do que o sistema educacional. Paulo Freire, decerto um dos escritores mais citados do Brasil, abordou o modo como a sociedade se torna padronizada. Em seu texto da década de 1970, ele declarou que "os homens começam a pensar e agir de acordo com as prescrições recebidas diariamente dos meios de comunicação, em vez de reagir às suas relações dialéticas com o mundo". (Freire, 1970, p. 80)

Quase 50 anos depois dessa declaração profética, o estudo do Brasil ora exposto tentará deixar clara a posição da qual os jovens brasileiros imaginam seu futuro. Estarão eles limitados pelo que Freire chamou de realidade opressiva imposta pelo poder da elite? A última frase de Freire em seu livro resume sua posição: "se temos fé nos homens, não podemos nos contentar em dizer que eles são pessoas humanas enquanto nada fazem de concreto para que possam existir como tais". (Ibid p. 83)

$\mathrm{O}$ autor deste artigo esteve no Brasil diversas vezes, tendo vivido no país por boa parte de 2011 e visitado diferentes partes do país. A universidade escolhida para este 


\section{RevistAleph}

estudo representa uma das cidades mais importantes do Brasil. Uma vez que falava razoavelmente o português, o autor sentiu-se seguro de ter obtido uma variedade de vozes dos estudantes que frequentavam a referida universidade e que concordaram em participar deste estudo. A universidade escolhida no Rio de Janeiro é uma grande universidade com uma população estudantil diversificada.

\section{França}

Por ser um dos países-chave da Europa, o estudo da França ajuda a dar reconhecimento à voz da juventude europeia. Não há uma única voz que caracterize qualquer país ou continente; no entanto, dispor das esperanças e aspirações dos jovens franceses permitirá o surgimento de uma imagem sobre como a juventude francesa tem viajado atualmente. John Ardagh, ao escrever durante os anos 1980, disse que, porquanto a economia estagnada foi transformada em das mais dinâmicas e bem-sucedidas do mundo “... a prosperidade aumentou, trazendo consigo mudanças nos estilos de vida e lançando alguns conflitos estranhos entre os hábitos franceses já enraizados e os novos hábitos" (Ardagh, 1982, p.13). Como os franceses de hoje veem o mundo? Os franceses sempre se consideraram diferentes do resto do mundo. Os subsídios que pagavam aos fazendeiros para produzirem em pequenas fazendas antieconômicas tornaram-se motivo de risada na Europa, certamente por aqueles que eram membros da Comunidade Europeia.

Michael Crozier, um conceituado sociólogo dos anos de 1960, foi um daqueles... que ousaram esperar que a mudança econômica ajudasse a desbloquear a sociedade: em 1979 ele escrevia sobre a França como uma sociedade ainda estratificada a qual, em grande parte, progredira negativamente para uma maior rigidez - uma sociedade cujos cidadãos estão apaixonadamente presos a distinções e privilégios que os separam.

\section{Austrália}

Por que Sydney e Melbourne? Um dos impactos mais imediatos da globalização que a sociedade australiana sentiu resulta da criação de um mercado global. A mudança na localização da produção para os países com a oferta de mão de obra mais barata fez 


\section{RevistAleph}

com que desaparecessem muitos empregos tradicionais que funcionavam como porta de entrada para a força de trabalho. (O mesmo ocorreu na França e no Brasil). Essa mudança teve sérios desdobramentos para aqueles que entram no mercado de trabalho pela primeira vez, predominantemente os jovens. Uma das influências sobre os jovens que pretendem deixar a escola tem sido uma taxa de retenção aparente mais alta. Isso também significa que há um número maior de alunos frequentando instituições de ensino superior. O processo de seleção e triagem está sendo levado para o topo da cadeia da educação escolar/formal. A chamada transição do ensino superior de uma elite para um fenômeno de massa teve várias implicações; levou a uma inflação de qualificações no nível terciário, à medida que mais estudantes estão participando do ensino superior. Gary Becker (2002) aborda o capital humano como a principal forma de capital nas economias modernas. Em vez de indicadores econômicos, como a proporção de alunos por professor e taxas de progressão, Becker considera que o sucesso econômico dos indivíduos e, de fato, das economias dos países, depende da eficiência com que as pessoas investem em si mesmas. Ele observa que, embora a tecnologia possa ser o condutor de uma economia moderna, o capital humano é o combustível. Os estudantes australianos não competem mais apenas com candidatos australianos por empregos. Os cargos de ensino, especialmente no nível universitário, são ferozmente disputados por uma mão de obra globalmente móvel.

\section{Questões de Pesquisa}

O modo como as entrevistas foram conduzidas variou entre os países. Normalmente, o pesquisador fazia entrevistas individuais, gravadas em áudio e transcritas, que eram, então, enviadas de volta aos participantes e alteradas, quando necessário, para obter precisão. As entrevistas no Rio de Janeiro foram todas gravadas em vídeo e as transcrições foram feitas a partir das gravações.

As perguntas foram semi-estruturadas e os alunos foram incentivados sempre que necessário, caso não entendessem a pergunta ou necessitassem de esclarecimentos sobre algum aspecto da questão. Os alunos puderam se retirar das entrevistas a qualquer momento e todos se ofereceram para participar do estudo. A maioria dos alunos não tinha recebido as perguntas com antecedência e, com exceção dos estudantes brasileiros, 


\section{RevistAleph}

as entrevistas foram feitas individualmente. Os estudantes brasileiros eram predominantemente pós-graduandos de uma grande universidade no Rio de Janeiro.

A lista de perguntas a seguir foi feita a todos os participantes.

1. Conte-me um pouco sobre você?

2. De onde você é e o que faz atualmente?

3. Se você pudesse mudar três coisas no mundo, o que mudaria? (Imagine que você é a pessoa mais poderosa do mundo e que pode mudar qualquer coisa).

4. Onde você gostaria de estar daqui a cinco e daqui a dez anos?

5. Quando pensa sobre o futuro do mundo hoje, você pensa de forma positiva ou negativa?

6. Quando perguntei se você se importaria de fazer parte deste estudo sobre os jovens e o futuro, tem alguma coisa da qual não conversamos e você pensou que abordaríamos?

\section{O que os jovens brasileiros tinham a dizer}

Todos os jovens que participaram do estudo do Brasil eram estudantes ou professores da mesma universidade ${ }^{16}$. As entrevistas foram gravadas em vídeo e as respostas foram transcritas e agrupadas tematicamente. Como Creswell \& Plano Clarke (2007, p. 26) observam “... a análise dos dados qualitativos (palavras ou textos ou imagens) normalmente segue o caminho de agrupar as palavras ou imagens em categorias de informação e apresentar a diversidade de ideias reunidas durante a coleta de dados". A maioria dos participantes do Brasil foi entrevistada em língua portuguesa, mas alguns alunos estavam confiantes o suficiente para serem entrevistados em inglês.

Havia pouca dúvida de que eles estariam preocupados com eventos globais e suas respostas refletiram essa inquietação. O sentimento inicial que ecoou em muitas das entrevistas foi o de que o mundo estava em um lugar escuro, mas que havia sempre um caminho a seguir. Isabella, a primeira aluna a ser entrevistada no Brasil, identificou apenas duas coisas em sua resposta para a segunda questão, a qual perguntava se ela pudesse mudar três coisas no mundo, quais seriam. A primeira foi a violência no mundo, assim

\footnotetext{
${ }^{16}$ Fazer pesquisa em educação comparada nem sempre é simples. As entrevistas no Brasil foram realizadas em novembro de 2015. No dia seguinte à realização da primeira rodada de entrevistas, a universidade na qual os estudantes estavam localizados foi fechada indefinidamente pelo vice-reitor, pois havia uma grande crise fiscal. A universidade não pôde pagar sua equipe de segurança e os ascensoristas. Embora a oportunidade de prosseguir com as entrevistas estivesse perdida, as entrevistas iniciais que haviam sido gravadas em vídeo e suas transcrições foram capazes de fornecer uma série de respostas significativas.
} 


\section{RevistAleph}

como no Brasil. A segunda foi uma preocupação pessoal em querer que os exames ${ }^{17}$ para os quais ela estava se preparando fossem cancelados. Ela também expressou que queria saber falar melhor o inglês. Em cinco anos, ela esperava ter concluído o bacharelado e o mestrado. Em dez anos, ela gostaria de terminar seu doutorado. Seu pensamento sobre o futuro era positivo, mas ela achava que as grandes coisas que o mundo enfrentaria no futuro seriam "... a falta de pertencimento para as pessoas e a falta de tolerância".

Com relação aos três maiores problemas enfrentados no mundo, Adrianna respondeu que eram a falta de tolerância, a falta de comida e o fato de que tantas pessoas passavam fome diariamente, e o comportamento das pessoas. Em cinco anos ela esperava estar casada e ter uma família, ter concluído a graduação e estar a caminho de terminar o mestrado. Ela deixaria o Brasil em poucos meses para viver com sua tia em Noosa, Austrália, por um ano, e estava animada com isso e com as possibilidades que essa mudança poderia the oferecer. Ela achava que os grandes problemas enfrentados no mundo eram todos influenciados pela maneira como as pessoas pensam sobre o mundo e sobre seu lugar nele. Ela achava que, se as pessoas pudessem mudar sua perspectiva e não serem tão egoístas, o mundo seria um lugar muito melhor. Em outras palavras, os problemas do mundo não seriam necessariamente problemas se não os considerássemos como problemas.

Para Sylvie, o mundo carece de valores e se beneficiaria de mais orientação para as pessoas, razão pela qual ele é do jeito que é. A desigualdade é outro problema, causado por um grande número de pessoas que têm muito enquanto outros não têm nada. Em terceiro lugar, há muitos problemas se as pessoas não levam a religião em consideração. Segundo Sylvie, a falta de Deus nas vidas das pessoas é um problema. Em cinco anos, ela deseja ter terminado os estudos. Ela deseja prestar concurso e conseguir um cargo na força aérea ou na polícia, sendo que não se importaria de se tornar professora. Em dez anos ela quer se casar e ser feliz. Ela acha que, se estiver no exército, estará bastante satisfeita, uma vez que vai estudar judô e o exército dispõe de esportes para os militares em seu tempo livre. Sylvie sente que à sociedade faltam amor e a crença em Deus. Segundo ela, a quando se age com frieza perante os sentimentos, é aí que o problema

\footnotetext{
${ }^{17}$ Isabella esperava continuar seus estudos após o término de seu curso de graduação no Brasil e, para isso, precisava fazer os exames externos para se classificar.
} 


\section{RevistAleph}

começa. A estrutura familiar é muito importante para a sociedade de hoje. Se não se tem uma estrutura familiar forte, então não se tem uma sociedade forte e resiliente.

Adriane era a estudante com maior idade; tinha 37 anos, era casada e mãe de dois filhos. Havia se graduado no ano anterior e agora cursava o mestrado. Ela desejava transformar a pobreza no mundo e sentia que, embora houvesse muita riqueza, esta não era igualmente distribuída. Em segundo lugar, ela gostaria de poder mudar a relação que coloca uma barreira entre a capacidade de ter filhos e a de trabalhar ao mesmo tempo. Sentia que estava perdendo a chance de saber como os próprios filhos agiam. O terceiro problema enfrentado no mundo, segundo a aluna, era o egoísmo, algo impossível de mudar, uma vez que está ligado à natureza humana. No espaço de cinco anos, ela desejava terminar o ou estar em processo de finalização do doutorado. Também pretendia comprar uma casa nova (deu risadas) e continuou a listar algumas coisas de que precisava.

Em dez anos, ela gostaria de ter passado em algum concurso público bem como ver seus filhos crescerem e acompanhá-los em suas conquistas. Para ela, o egoísmo é o maior problema a ser enfrentado no mundo. De acordo com a aluna, pensamos que nossos problemas são os mais sérios e que os dos outros são menos importantes. Ela disse que, quando tinha 18 anos, crianças e suas necessidades não passavam pela sua cabeça. Porém, desde que começou a estudar pedagogia e a participar de eventos sobre exclusão, passou a refletir intensamente sobre crianças e o quanto poderiam perder com suas mães trabalhando.

Taibaniz era uma aluna de 23 anos que pensava ser a política ${ }^{18}$ o problema central. Ela sentia que “... geralmente havia uma falta de engajamento por parte dos brasileiros. A polícia também era problemática, entretanto, a política e seus líderes no poder não faziam o suficiente para mudar, em particular, a educação dos adultos, o que poderia colaborar para fazer a diferença na criação de uma sociedade mais igualitária". Em cinco anos, ela terá completado o mestrado e começado a trabalhar ou a cursar o doutorado. Ela acredita que, se estiver trabalhando com política ou políticas públicas, tem ideias que poderão ajudar a mudar o ambiente político da Universidade. Ela realmente

\footnotetext{
18 Dilma, a presidente do Brasil à época, não havia sofrido o impeachment no momento dessa entrevista. O Brasil não havia sido a sede das Olimpíadas, mas havia sediado com sucesso a Copa do Mundo de Futebol em junho-julho de 2014.
} 


\section{RevistAleph}

acha que há uma falta de tolerância à diferença e às divergências entre as pessoas dentro da sociedade: "Todo mundo está convencido de que a sua opinião é a correta."

Taina tem 21 anos e concorda com Taibaniz de que os principais problemas no mundo são causados pela política. O acesso desigual à educação e aos serviços de saúde também criam complicações. Em cinco anos, Taina acha que vai estar em alguma cidade pequena, trabalhando com crianças. Se tudo der certo, ela terá completado seu mestrado até lá: "O maior problema de todos é falta de compaixão pelos outros".

Roberta acredita que as pessoas precisam ser menos egoístas; elas não deveriam ser tão obcecadas com o poder e serem capazes de se colocarem no lugar dos outros. Roberta acha que as pessoas precisam ter mais entusiasmo e demonstrar compaixão umas pelas outras. Ela está muito aberta para o futuro, pois não gosta muito de fazer planos. Em cinco anos, ela espera ter se estabilizado em sua carreira de alguma forma e estar em condição de ajudar sua família de um modo mais substancial. Ela assinala que tem uma tia nos E.U.A. e que gostaria de visitá-la e passar algum tempo com ela. Roberta deseja encontrar um marido por agora e acredita ser esta uma tarefa realmente difícil.

O maior problema citado por ela, assim como Adriane e Taibaniz, é que "as pessoas são egoístas e não pensam nas necessidades dos outros. Elas pensam somente em si mesmas e em suas esperanças e necessidades. Esse é o maior problema".

Marcel realmente acredita que o acesso à educação é a questão mais importante. Isso porque as pessoas que têm dinheiro possuem uma vantagem, pois podem frequentar uma escola particular e, depois, uma Faculdade de Medicina ou Universidade. Pessoas que frequentam escolas como a dele em Nova Iguaçu ${ }^{19}$ geralmente não têm chance de frequentar um Programa de Doutorado em uma Universidade ou de se tornarem profissionais como médicos e advogados.

Em segundo lugar, Marcel mudaria as opiniões das pessoas sobre o "outro", porque sentia que os moradores de ruas não recebiam muita simpatia: "Não é falta de

\footnotetext{
${ }^{19}$ Nova Iguaçu localiza-se no subúrbio do Rio de Janeiro, onde o professor com quem o autor deste artigo estava trabalhando no Brasil realizava um estudo de caso para outro projeto, com o qual o autor deste artigo também estava envolvido. Tratava-se de um estudo em andamento, o qual investigava uma série de questões que afetavam o acesso dos alunos ao estágio seguinte de sua educação. A Diretora Adjunta da escola estava ciente de que os alunos, após o término do ensino médio, não conseguiam efetuar, de forma tranquila, a transição para o próximo estágio de sua escolarização. $O$ autor deste artigo esteve pessoalmente envolvido nesse projeto por mais de cinco anos, e um dos destaques de seu estudo em 2015 foi observar que os alunos envolvidos no projeto anterior conseguiram realizar a passagem para o ensino superior. Marcel foi um deles.
} 


\section{RevistAleph}

amor. As pessoas adoram ser amadas. As pessoas ficam desapontadas com um amor gay e isso as impede de fazerem coisas". Ele acreditava que havia fascinação com o dinheiro ${ }^{20}$. Em dez anos, ele gostaria de terminar seus estudos em Psicologia e de seguir até o Doutorado: “Não em Psicologia, mas em Educação".

Ele achava que a coisa mais importante era as pessoas terem empatia umas pelas outras: “... não é a falta de amor que desafia o mundo, é simplesmente que as pessoas precisam ser amadas."

Gabriella estava convencida de que os maiores problemas enfrentados no mundo eram “... a desigualdade de acesso à educação, respeito pelas vidas dos outros, falta de amor pelos outros, os conflitos políticos e fanatismo religioso". Em cinco anos ela espera ter obtido seu título de Mestre e ter passado em um concurso público como seu emprego no futuro. O maior problema enfrentado no mundo, segundo a aluna, era a "... falta de amor pelos outros e a falta de respeito pelas vidas dos outros".

Juliana foi muito clara sobre os problemas enfrentados no mundo atualmente. $\mathrm{O}$ primeiro seria "... a natureza dos relacionamentos humanos. Porque o egocentrismo e o comportamento da natureza humana levam as pessoas a fazerem as coisas por interesse pessoal e pelo que vão ganhar em troca". O segundo seria o relacionamento entre o homem e a natureza ${ }^{21}$. O terceiro seria a desigualdade entre as pessoas e, certamente, os países.

Em cinco anos, ela espera obter o grau de Mestre e estar em condição de colaborar com o sustento de sua família. Ela deseja ficar sozinha. Em dez anos, irá terminar seu doutorado "... e viajar de alguma forma para outros países e culturas".

Ela mencionou que, enquanto estava em escolas, observando outros professores ensinando, estes frequentemente perguntavam a ela qual seria o problema com a educação e o que poderia ser feito para melhorá-la. Ela disse que não sabia realmente o que responder a eles e que os professores sempre “... desistem dos alunos, desistem das aulas e nunca descobrem como chegar até os alunos".

\footnotetext{
${ }^{20} \mathrm{O}$ autor deste artigo perguntou a Marcel nesse ponto da entrevista se ele achava que se os alunos estivessem se comunicando sobre as questões, as respostas seriam diferentes. Segundo Marcel, se houvesse uma conversa como essa com os alunos "... tudo seria muito mais solto em termos de respostas, mas, no final, as mesmas coisas seriam ditas".

${ }^{21} \mathrm{Com}$ isso, ela queria se referir à forma desrespeitosa pela qual a humanidade trata o meio-ambiente.
} 


\section{RevistAleph}

Ela acredita que pode não ter nada de errado, mas quando os alunos são questionados sobre quem seria seu professor favorito, eles respondem Sr. ou Sra. X e quando expressam a razão da escolha dizem “... porque o professor se importa com a gente. Ele ou ela gosta deles."

Luís Paulo é professor em uma escola primária no Rio de Janeiro e acha que terá que mudar a si mesmo antes de mudar o mundo, sendo este o primeiro problema: "Acho que eu tenho que mudar a mim, minha posição e minha perspectiva". Em segundo lugar, ele acha que terá que mudar o lugar onde vive, seu trabalho e sua Universidade. O maior problema que vê no Brasil é a política. Segundo ele, a corrupção no governo é ruim.

Luís Paulo não tem irmãos ou irmãs e, em cinco anos, ele se vê terminando o Doutorado com seu professor. Provavelmente, irá comprar um carro e uma casa: "Acho que vou precisar de um bom emprego".

Ele não sabe o que vai fazer em dez anos, mas respondeu: “... talvez eu esteja empregado em uma universidade e tenha meu grupo com pós-graduandos e alunos, e isso possa organizar minha vida. E serei feliz".

Ele observa que "...talvez seja uma questão sobre economia, governo e o modo como o dinheiro é administrado... não é muito bem administrado... há muita desigualdade".

A última entrevista formal gravada foi com Suzianne, uma doutoranda. Ela tinha 34 anos e era casada. Quando respondeu sobre as três coisas que precisavam ser mudadas, ela começou com a educação: “Não somente o acesso, mas o modo como é feita. Por exemplo, aqui no Brasil temos pensado sobre o sistema. Acho que é importante que seja mais focado no aluno. O aluno como elemento central [...] Acho que o segundo é a desigualdade. Quando não temos um bom sistema educacional é o mesmo que desigualdade [...] E eu acho que o terceiro é a intolerância. Se não temos uma boa educação não temos igualdade, não temos tolerância".

Em cinco anos, ela espera ter terminado seu doutorado e ter um emprego. Ela complementa dizendo que gostaria de ser mãe, de ter filhos: “É um plano... A verdade é que, normalmente, eu tenho esse tipo de plano por um ano. Mas, não agora, (a família), preciso de um emprego e depois sim (engravido)." Ela disse que esteve na Inglaterra no ano anterior: "Não era meu plano". 


\section{RevistAleph}

Ela comentou que dez anos é um longo tempo: “Dez anos é muito longe do aqui e agora, mas eu quero continuar casada. Quero ter mais filhos, porque eu quero uma família grande, com três filhos - gosto de crianças".

Ela acrescentou que havia muitas razões para o mundo ser como é. Ela era geralmente positiva sobre o futuro do mundo, mas achava que muitas coisas precisavam mudar, e a educação tem um papel fundamental para as mudanças necessárias. Em suas próprias palavras “... se parar e der uma olhada, poderá ver que a educação é um fator, uma coisa forte. Há uma falha política; existe uma tolerância, não uma coisa só. Muitas e diferentes coisas.

\section{O que os jovens franceses tinham a dizer}

As primeiras três entrevistas com estudantes franceses foram realizadas em agosto de 2016. Duas foram feitas em francês e uma em inglês. Jennifer, esse não era seu nome verdadeiro, tinha acabado de fazer 30 anos. Falava inglês muito bem e a conversa se desenvolvia em turnos, em francês e inglês. Ela havia nascido em Saint Lazare, onde seu pai trabalhava para a Aérospatiale (agora conhecida como Airbus). O pai e toda a família se mudaram para Melbourne, na Austrália, onde ficaram por três anos e, no retorno à França, o pai foi alocado em Toulouse. Isto é o que ela tinha a dizer:

Bem, sou Jennifer, sou de Toulouse. Estudei por quatro anos para exames preparatórios (A-Levels) em Ciências Políticas. Durante esse período, tive a oportunidade de realizar muitos treinamentos. Optei por um treinamento em comunicação, mas, após realizá-lo, percebi que não era para mim. Então, decidi tentar a Escola de Negócios ... Optei por uma carreira em finanças... e, depois do meu último ano de estudos, decidi ir para a Deloitte, onde estive por seis anos e, há dois meses, decidi ir para um nova companhia, onde estou também envolvida com planejamento financeiro, mas em uma firma pequena.

Quando perguntada se consideraria se mudar da França no futuro devido ao trabalho, ela disse: "Sim, bem... eu gostaria, mas estou em um cargo sênior e uma transferência significaria que custa caro me empregar. Eu poderia ter imaginado ir para o exterior, mas... acho que nos E.U.A. é muito difícil conseguir um visto. No Reino Unido está bem complicado com o Brexit e não é fácil agora. 


\section{RevistAleph}

Os maiores problemas enfrentados no mundo, e na França, em particular, suscitaram a seguinte resposta: "Bem, na França, um dos principais problemas são os ataques terroristas e a questão da segurança, ao mesmo tempo em que asseguram que ainda estamos em um sistema democrático. Então, qual é o equilíbrio entre segurança e liberdade? O Big Brother (está) observando você".

Entrevistador: A França parece ter sido gravemente afetada.

Jennifer: Acho que é algo a se observar, sobretudo na minha idade. Em finanças, é algo que tem muita influência econômica no meu mundo, especialmente no trabalho. Principalmente com os ataques terroristas. Soube que o número de turistas caiu $40 \%$, então, isso vai afetar a economia de qualquer forma.

Segunda preocupação: "Como vamos encontrar empregos? Então, é um grande problema."

Terceira preocupação: "Outra grande questão é o problema do meioambiente. Ouvimos falar sobre essas doenças relativas ao consumo de carne, a doença da vaca louca. Então, todas as nossas indústrias estão poluindo. Não sabemos o que vai acontecer com nossas indústrias."

"Outra coisa, é como vamos lidar com a desigualdade no mundo, porque, na França, agora, obviamente estamos muito bem. Temos direitos, mas o que vai acontecer com outros países - onde as pessoas não têm direitos?"

"Como vamos avançar e não regredir? Há muitos problemas globais, e eles são problemas-chave. A ONU é ainda uma organização capaz de enfrentar os problemas que temos? Penso que estamos em uma espécie de agitação, e ninguém está colaborando, e nada está acontecendo." Entrevistador: Onde acha que vai estar daqui a cinco e daqui a dez anos? Jennifer: "Provavelmente, daqui a cinco anos estarei em Paris. Agora, em dez anos, é possível que ainda esteja em Paris, mas em outro emprego em outra companhia. Gostaria de estar em um país em desenvolvimento e ajudar no seu direcionamento. Mas isso é um pouco fantasioso. Uma vez que você começa um trabalho (emprego) e está indo bem, você deseja ficar ali porque fica com medo do futuro."

Quando perguntada se havia algo sobre o qual não havíamos conversado e que achava que deveria ter sido abordado, Jennifer apresentou mais duas respostas. Ela se questionava se havia algo que Ihe poderia ter sido dito e que teria tornado as coisas mais fáceis para sua transição para o emprego. Ela sentia que "... os novos alunos querem se divertir em suas vidas e não somente trabalhar. Os novos alunos não são consumidos pela conexão entre o que querem fazer e o desejo de ter um emprego".

Ela continuou, dizendo que achava que a cada cinco anos ou mais é necessário complementar o CV e fazer mudanças. A próxima geração “... não está tão perturbada com a hierarquia." 


\title{
RevistAleph
}

Suzie era de Carpentras, no sul da França, e tinha 19 anos quando foi entrevistada. Possuía uma educação francesa clássica, tendo feito seu Baccalaureate em estudos científicos. Era jovem (16 anos) quando completou o ensino médio e saiu de casa para continuar os estudos. Logo depois, em Marselha, realizou os estudos preparatórios para Engenharia. Achou difícil deixar os pais, pois era muito próxima a eles, e sentiu-se “... muito sozinha durante os anos preparatórios para a universidade. Era difícil para mim a adaptação a uma nova cidade, embora eu sempre tenha vivido em uma cidade menor. $\mathrm{E}$ não conhecer ninguém.".

Após concluir o competitivo exame de admissão, Suzie foi para Paris para a Grand École a fim de iniciar o curso de três anos para ser engenheira, especializada em Engenharia Mecânica. Obteve o grau de engenheira mecânica e estava prestes a fazer um estágio de seis meses na Suíça na Richemont, um famoso grupo relojoeiro:

Então, vou voltar a Paris e gostaria de passar um tempo no Canadá para obter um duplo diploma... Eu sei que é impensável para uma engenheira não viajar. Agora, se não nos abrimos para o mundo, aprendendo novas línguas, vendo como os outros estão trabalhando em diferentes países, sabemos que estamos nos fechando a algumas oportunidades interessantes para nossa carreira.

Como resposta à questão de onde gostaria de estar dali a cinco e dez anos, ela disse:

\begin{abstract}
Ok, nos próximos cinco anos eu gostaria de viajar muito mais. É que eu gostaria de viajar com meu namorado, mas não é fácil para nós viajarmos juntos, já que não trabalhamos na mesma área. Eu gostaria de viajar e estar com ele, mas não gostaria de chegar aos 30 e, então, pensar que perdi a oportunidade de ter filhos [...] Acho que, mais do que nunca, temos que escolher entre a carreira e a família muito cedo. Tenho 19 anos e já penso muito sobre isso. Como engenheira, vou ter que passar dez horas trabalhando, mais o tempo de deslocamento. E as oportunidades estão concentradas em Paris. Mas eu não quero criar meus filhos em Paris de jeito nenhum! Então, o trabalho cada vez mais toma uma grande parte de nossas vidas. Por exemplo, eu tenho uma amiga e uma prima que estão esgotadas, embora tenham menos do que vinte anos!
\end{abstract}

A terceira entrevista em francês foi realizada com Pierre, que havia acabado de se formar na escola e tinha 18 anos. Ele mora em Tournefeuille ${ }^{22}$ com seus pais. Espera

\footnotetext{
${ }^{22}$ Tournefeuille é um subúrbio fora de Toulouse.
} 


\section{RevistAleph}

trabalhar com design no futuro e, possivelmente, com administração no campo da distribuição de produtos. Passou cinco anos na escola na Itália e é bilíngue em francês e italiano. Sua família havia se mudado novamente para a França para que ele completasse seus estudos (Baccalauréat Général). Pierre observou que as universidades na França aceitam os alunos de acordo com a especialidade que escolhem.

Para Pierre, os problemas mais significativos atualmente enfrentados no mundo eram “... o problema do terrorismo, porque há pessoas que matam e não sabem o que é certo ou errado. Outro problema são as doenças, que globalmente destroem as famílias. O terrorismo, desde novembro (2015), aumentou. Um problema real em todo mundo, não somente na França. Elas desejam mudar o modo e o estilo de vida. As fontes de energia também são um problema. Se não forem diversificadas, o mundo terá grandes dificuldades no futuro. Usar menos os carros... todo mundo precisa fazer isso. Em alguns países, como, por exemplo, na África, não é possível pedir isso às pessoas. Mas em países desenvolvidos, como a Europa, os Estados Unidos etc.. elas usam a energia.

Luke acha que nos próximos cinco anos estará estudando, e que em mais cinco anos estará trabalhando na área de design. Definitivamente, gostaria de estar morando sozinho, sem os pais. "Não acho que vou estar casado. Não penso nisso no momento."

A mídia influenciou fortemente a posição dele sobre o modo como será o futuro: "Se vemos, observamos a mídia, ela não é legal. Mas as coisas parecem ruins... Sim, para a mídia; acho que as coisas mais interessantes são negativas. Eles falam de jogos, mas não de política. A mídia manipula os resultados".

\section{O que os jovens australianos tinham a dizer?}

O primeiro australiano a contribuir com o estudo foi Roger. Ele cresceu em Melbourne e frequentou a mesma escola particular dos três aos doze anos. Na época da entrevista, estava no processo de término de sua graduação na área do comércio. Tinha acabado de completar 20 anos, morava em Melbourne e estudava na universidade. Havia viajado entre a Nova Zelândia e a Austrália, mas nunca tinha se mudado de Melbourne. Quando perguntado sobre os três maiores problemas enfrentados no mundo, respondeu que: 


\title{
RevistAleph
}

\begin{abstract}
"Bem, me veio à cabeça três coisas e elas meio que estão interligadas e representam um panorama geral. O primeiro é o problema da população, depois o do esgotamento dos recursos naturais e, finalmente, o da desigualdade. $E$ os três estão interligados. Acho que o fato de haver populações enormes em países que não são sustentáveis, e de os recursos serem finitos e da desigualdade de pessoas que querem fugir da pobreza e também o da distribuição desigual dos recursos globalmente [...] Bem, acho que a questão da sustentabilidade dos recursos e como vamos fazer isso [...] Precisamos encontrar uma maneira diferente de viver de forma sustentável. Acho que há questões de curto-prazo com as quais precisamos lidar, já que, quando se tornam de longo-prazo, temos problemas".
\end{abstract}

Quando perguntado sobre onde gostaria de estar dali a cinco ou dez anos, ele tinha o seguinte a dizer:

Tenho pensado muito sobre isso, mas não cheguei a muitas respostas. Depende de eu optar por começar a trabalhar ou por outro diploma. Antes era mais fácil, quando a gente não precisava se preocupar com mensalidades e simplesmente começava outro curso. Mas ao procurar, a gente realmente precisa se preocupar. Motivo de muita reflexão por parte daqueles que estudam Arte. No início do terceiro ano eles começam a perceber que não têm nada em termos de trabalho.

Entrevistador: Mas, e daqui a dez anos?

Roger: Sim, quantos anos vou ter até lá, 30 anos. Sim, é melhor eu ter me virado até lá. Mas eu acho o mesmo, quero estar mais estabilizado em cinco anos. Emprego, fazer muita música, e esporte, e coisas.

Entrevistador: Ok, então quando pensa sobre o futuro, você o vê de uma maneira positiva? Você tem dúvidas?

Roger: "Acho que, no momento, estou bem negativo. Um pouco, sim, me sinto bem desanimado por não ter ideia sobre como o futuro vai ser! Vejo um monte de gente que sabe o que quer fazer. É sempre o que você vai fazer quando crescer e, então, vira o que você vai fazer depois das provas de admissão e, então, o que você vai fazer no próximo ano... então é sempre a mesma coisa."

\section{Discussão dos resultados}

Há pouco para indicar que os alunos estavam apreensivos sobre seu futuro no Brasil. Embora os eventos nem sempre indiquem o futuro como um caminho seguro e garantido em qualquer país, os alunos brasileiros parecem estar realmente abraçando o futuro. Todos estavam, é claro, muito bem posicionados para lidar com a vida, pois tinham conseguido chegar à Universidade e estudar. O sistema de educação no Brasil é, para muitos, difícil de administrar e, como Marcel observou, era incomum que as pessoas de sua escola chegassem à Universidade. Ele e vários outros alunos de sua escola 


\section{RevistAleph}

conseguiram chegar ao ensino superior (terciário). Este caminho era mais facilmente enfrentado por aqueles que tinham maior poder aquisitivo para ajudá-los a entrar no sistema universitário privado ou público.

Talvez, o tema mais consistente levantado pelas respostas dadas pelos jovens brasileiros seja a necessidade de maior tolerância e amor entre as pessoas.

A maneira pela qual as entrevistas foram realizadas influenciaram alguns dos comentários dos participantes. Por terem ouvido as resposta uns dos outros, em vez de serem entrevistados individualmente, os estudantes podem ter se adaptado ou tomado emprestado o que tinham a dizer. A ideia de uma situação de grupo focal como esta objetivava encorajar o debate, e não influenciar as respostas.

\section{Conclusão}

Os alunos que responderam nesta seção do estudo pareciam inseguros sobre a maneira como o futuro iria se apresentar a eles, mas sentiam-se confortáveis com o grau de incerteza que viam à sua frente. A preocupação com toda a sociedade, e não somente com o a área que ocupavam, foi óbvia. Como Juliana observou acima, quando perguntada sobre as três coisas que desejava mudar, a primeira a ser comentada foi: "a natureza dos relacionamentos humanos. Porque o egocentrismo e o comportamento da natureza humana levam as pessoas a fazerem as coisas por interesse pessoal e pelo que vão ganhar em troca".

Kitty te Riele (Bagnall, 2005, p. 48) escreveu sobre o processo de transição da juventude para a vida adulta como “... inevitavelmente afetado pelo contexto social, cultural, econômico e político da sociedade na qual o jovem vive". Ela argumenta que, com a transição das nações desenvolvidas contemporaneamente para uma economia baseada no conhecimento, o "momento de transição para o emprego e para a vida adulta independente foi, assim, adiado".

Todos os cinco países envolvidos neste estudo são nações desenvolvidas e estão em quatro continentes. As entrevistas feitas neste estudo abrangem jovens com idades de 18 a 30 anos, alguns deles exercendo atividades profissionais e muitos realizando seus estudos no momento em que as entrevistas foram realizadas. Eles mantiveram uma perspectiva positiva apesar das nuvens sombrias no horizonte. Desde a última entrevista, 


\section{RevistAleph}

um novo Presidente foi eleito no país considerado o mais poderoso do mundo. 0 direcionamento global do cenário político vem sendo abalado até o centro. Talvez Adriane, Taibaniz e outros estejam corretos em suas afirmações sobre o maior problema ser que "as pessoas são egoístas e não pensam nas necessidades dos outros. Elas pensam somente em si mesmas e em suas esperanças e necessidades. Esse é o maior problema".

\section{REFERÊNCIAS:}

BAGNALL, N. F. (ed.). Youth Transition in a Globalised Marketplace. New York: Nova Science Publishers, Inc., 2005.

BAGNALL, N.F. Education and Belonging. New York: Nova Science, 2012.

BAGNALL, N.F. Global Identity in Multicultural and International Educational Contexts. Student identity formation in international schools. Routledge London and New York, 2015.

BECK, G. In: Lauder, H., BROWN, P., Dillabough, J., Halsey, A.H., (2006). Education, Globalization and Social Change. New York: Oxford University Press, 2002.

BUCX, F. Linked Lives. Young Adults' Life Course and Relations with Parents. Dissertation. Utrecht: Utrecht University, 2009.

CAIRNS, D. Youth transitions, international student mobility and spatial reflexivity. Being Mobile? United Kingdom: Palgrave Macmillan, 2014.

CHOPRA.; GAJJALA, R. (Eds). Global media, culture, and identity: Theory cases and approaches. New York, NY and London Routledge, 2011.

CRESWELL, J.W.; PLANO CLARKE, V. L.,. Designing and conducting mixed methods research. Thousand Oaks, CA: Sage, 2007.

CROZIER, M. On ne change pas la société par décret. Paris: Bernard Grasset, 1979.

DALY. M. Changing Family Life in Europe: Significance for State and Society. European Societies 7 (3), 379-398, 2005.

Freire, P. Pedagogy of the Oppressed. New York: Herder and Herder, 1970.

FREJKA , T.; SOBOTKA, T. Overview Chapter 1: Fertility in Europe. Diverse, Delayed and Below Replacement In: T.Frejka, J. Hoem, T. Sobotka, and L. Toulemon, Childbearing Trends and Policies in Europe An Overview, Demographic Research, Volume 19, Max Planck Demographic Institute, 15-46, 2008.

GALLAND, O. 'What Is Youth?' In: A. Cavalli and O. Galland (eds) Youth in Giampapa, F., \& Lamoureux, S. A. (2011). Voices from the field: Identity, language, and power in multilingual research settings. Journal of Language, Identity \& Education, 10(3), 127-131, 1995.

HANTRAIS, L. 'Living as a Family in Europe' In: L. Hantrais, D. Philipov, F.C. Billari, Policy Implications of Changing Family Formation, Population studies no.49. Council of Europe Publishing, pp.117-181, 2006. 


\section{RevistAleph}

KAUFMANN, F.X. 'Politics and Policies towards the Family in Europe' in Knijin, T., (2012). Work family policies and transitions to adulthood in Europe. UK, USA: Palgrave Macmillan, 2002.

LANDIS, D., BENNETT, J.M., BENNETT, M.J., (Eds), Handbook of intercultural training. $\left(2^{\text {nd }}\right.$ ed., 163-188). Thousand Oaks, CA: Sage.

LEWIS , J. Work-Family Balance, Gender and Policy (Cheltenham, UK, and Northampton, Massachusetts, USA: Edward Elgar Publishing Ltd), 2009.

MARKAUSKAITE, L.; FREEBODY, P.; IRWIN, J. Methodological choice and design:

Scholarship, policy and practice in social and educational research. New York, NY:

Springer, 2011.

MILES, S. Youth Lifestyles in a changing world. Buckingham: Open University Press, 2000.

MULLINGS, B. Insider or outsider, both or neither: some dilemmas of interviewing in a cross-cultural setting. Geoform, 30, 337-350. no.49. Council of Europe Publishing, 117181, 1999.

SARACENO, C. 'Introduction: Intergenerational Relations in Families: A Micro-macro Perspective' in C. Saraceno (ed.), Families, Ageing and Social Policy. Intergenerational Solidarity in European Welfare States (Cheltenham, UK, and Northampton, MA, USA: Edward Elgar Publishing Limited), 1-19, 2008a.

SCHMID, G. 'Social Risk Management through Transitional Labour Markets'. SocioEconomic Review 4, 1-33, 2006.

SOBOTKA, T.; L. TOULEMON. 'Overview Chapter 4: Changing Family Society'. European Societies 7 (3), 379-398, 2008.

VERTOVEC, S.; COHEN, R. Conceiving Cosmopolitanism: Theory, Context, and Practice. Oxford: Oxford University Press, 2002. 